Journal of Accident and Emergency Medicine 1994 $11,168-171$

\title{
Acute bacterial diarrhoea in the emergency room: therapeutic implications of stool culture results
}

\author{
N. KAMINSKI, V.BOGOMOLSKI \& R.STALNIKOWICZ
}

Department of Internal Medicine, Hadassah University Hospital, Mount-Scopus, Jerusalem, Israel

\section{SUMMARY}

Empiric treatment with ciprofloxacin and norfloxacin has been recommended recently for patients with acute diarrhoeal disease. In a retrospective 6-month study period the results of stool cultures from 209 patients with acute diarrhoea admitted to the emergency room were analysed. Seventy-eight cultures $(37 \%)$ were positive for one or more bacteria. Shigella was the most commonly isolated pathogen (68\%). Shigella sonnei comprised $72 \%$ and Shigella flexneri $19 \%$ of all the bacterial isolates. While no antimicrobial resistance to ciprofloxacin was found for both Shigella species, only 36 and $26 \%$ of the Shigella isolates were sensitive to ampicillin and trimethoprim-sulfamethoxazole (TMP-SMZ), respectively. These findings point out to the emergence of drug resistance to commonly used antimicrobial drugs. Shigella's high sensitivity to the newer quinolones should make this the treatment of choice for the very sick patient, although physicians should be cautioned to the fact that indiscriminate use of this drug could result in the emergence of resistance similar to that noted with ampicillin and TMP-SMZ.

Key words: diarrhoea, drug resistance, empiric treatment, quinolones.

\section{INTRODUCTION}

Acute diarrhoeal disease is a common complaint in the setting of emergency rooms in community and university hospitals, especially during summer time. Up to $50 \%$ of acute diarrhoeal cases found in this setting are caused by bacteria. ${ }^{1}$ Traditional therapeutic approaches include correction of fluid and electrolyte abnormalities and antibiotic treatment in selected cases. Empiric antibiotic treatment has recently been advocated, as antimicrobial agents have been successful in the treatment of shigellosis, enterotoxigenic $E$. coli and traveller's diarrhoea. $^{2-6}$ The prevalence of bacterial patho- gens and their antibiotic sensitivity is of major importance in the choice of empiric antimicrobial agents. Reports on the emergence of bacterial strains resistant to commonly used antibiotics ${ }^{7-11}$ make both the decision to treat and the choice of the empiric agent difficult. A retrospective survey has been conducted on the results of stool cultures from patients admitted to the emergency room with acute diarrhoeal disease. The purpose of the study was to determine which are the most common causative pathogens and their antibiotic sensitivity.

\section{METHODS}

All the results of stool cultures obtained from patients with acute diarrhoea attending the emergency room from May 1991 to September 1991, were retrieved from the computer. The samples were cultured according to standard methods described elsewhere and tested for sensitivity to different antibiotics in the standard disc method. ${ }^{12--13}$ The antibiotic sensitivity of pathogens was analysed for TMP-SMZ, ampicillin and ciprofloxacin. The results of the cultures were reviewed retrospectively and so were the emergency room charts of the patients. The severity of the illness was assessed according to the presence of temperature, signs of dehydration, clinical dysentery and the impression of the attending physician, resulting in the need of antibiotic administration and/or hospital admission. When examined, the presence of fecal leucocytes was also recorded.

\section{RESULTS}

A total of 209 stool cultures were available for analysis, one for each patient. In 78 samples (37\%) an enteric pathogen was isolated. Shigella (S.) species were the most common group of bacteria, comprising $68 \%$ of all the positive bacterial isolates (Fig. 1). S. sonnei was the single most common 
Acute bacterial diarrhoea in the emergency room

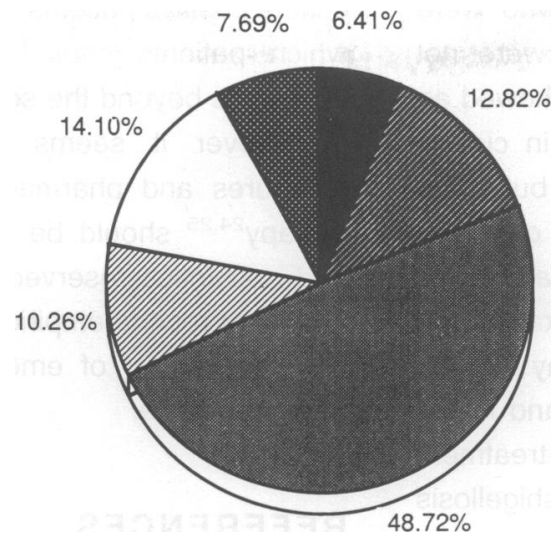

Fig. 1. Occurence of enteric pathogens in positive stool

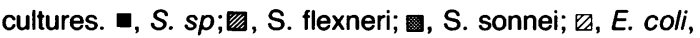
, Salmonella sp. and $\mathbf{D}$, Campylobacter.

isolate followed in decreasing frequency by $S$. flexneri, S. boydii and $S$. dysenteriae. The rest of the positive cultures included salmonella species, E. coli and finally Campylobacter species. Antibiotic susceptibility, as shown in Table 1, reveals that all the bacterial isolates were sensitive to ciprofloxacin. Only 36 and $26 \%$ of the shigella isolates were sensitive to ampicillin and TMP-SMZ, respectively. The patients included in the study acquired their enteric infection domestically; their age ranged between 1 to 86 years (mean 24.2 years). The severity of the diarrhoea could not be accurately evaluated from the patients charts. Fever $>38^{\circ} \mathrm{C}$ was present in $49.7 \%$ of the patients, vomiting in $35.8 \%$ and abdominal pain in $45.4 \%$ of the patients. Fecal leucocytes were examined only in 32 patients; 26 smears were found positive for the presence of leucocytes and 18 of them yielded a positive bacterial culture (Shigella species in 14 out of 18 ). Six smears were found negative for the presence of leucocytes and only one of them yielded a positive bacterial culture. Fifty-two patients were treated with antibiotics, of them $29(37 \%)$ had positive stool cultures and $23(18 \%)$ had negative stool cultures. From the data found in the charts it was impossible to draw conclusions regarding the reasons leading the attending physicians to treat or not to treat the patients with antibiotics. There was no statistical difference between the groups in the number of patients with fever or those older than 65 years. The only consistent finding leading to antibiotic treatment was a positive fecal leucocyte examination; $69 \%$ of the patients with a positive test received antibiotic therapy as compared with none of the patients with a negative test. According to antibiotic susceptibility of the isolated fecal bacteria, only $48 \%$ of the patients received adequate treatment.

\section{DISCUSSION}

The present study clearly shows that a very high percentage of Shigella isolates (the most common bacterial pathogen in our area) are resistant to commonly used antibiotics such as ampicillin and TMP-SMZ. These results represent a significant change in the susceptibility pattern of enteric pathogens. Halpern et al. from Israel, ${ }^{14}$ compared the susceptibility patterns of the Shigella species over two periods, 1975-1979 and 1980-1985 and no significant difference was found regarding susceptibility to ampicillin and TMP-SMZ between the periods; 81 and $66 \%$ of $S$. sonnei were susceptible to ampicillin and TMP-SMZ, respectively during the period 1980-1985. The results for $S$. flexneri were 72 and $78 \%$, respectively during the same study period. When compared with this study, $60 \%$ of $S$. flexneri but only $29 \%$ of $S$. sonnei were susceptible to ampicillin and $80 \%$ of $S$. flexneri but only $13 \%$ of S. sonnei were susceptible to TMP-SMZ. Similar findings have been reported from Asia, ${ }^{7.8}$ Africa $^{9}$ and North America. ${ }^{10,11} \mathrm{~A}$ recent report of acute bacterial diarrhoea during Operation Desert Shield showed that 85 and $21 \%$ of Shigella species were resistant to TMP-SMZ and ampicillin, respectively. ${ }^{15}$ In this study, as in other recent studies, susceptibility to ciprofloxacin and other quinolone antibiotic was universal and indeed empiric antibiotic therapy with fluroquinolones has been recently recommended for the treatment of acute diarrhoea. ${ }^{16}$ Treatment with ciprofloxacin and norfloxacin compared with placebo shortened the duration of diarrhoea and

\begin{tabular}{lcccr}
\hline Pathogen & Ampicillin (\%) & TMP-SMZ (\%) & Ciprofloxacin (\%) & Total \\
\hline Shigella (all) & 36 & 26 & 100 & 53 \\
S. sonnei & 29 & 13 & 100 & 38 \\
S. flexneri & 60 & 80 & 100 & 10 \\
E. coli & 50 & 62 & 100 & 8 \\
Salmonella & 90 & 100 & 100 & 11 \\
\hline
\end{tabular}

Table 1. Antibiotic susceptibility of enteric pathogens 
increased the percentage of patients who were cured or improved; similar differences were not found for TMP-SMZ. ${ }^{16}$ Wistrom et al. ${ }^{17}$ showed an overall favourable effect of norfloxacin in culture positive patients and severely ill patients but not in culture negative patients or patients with campylobacteriosis. In patients infected with Shigella species, significant differences between the norfloxacin- and placebo-treated groups were found on day 2 in the accumulated number of patients cured and in the mean number of loose stools. On the last treatment day, 80 and $50 \%$ of the patients with shigellosis were cured in the norfloxacin and placebo groups, respectively. Norfloxacin was significantly less effective than the placebo in eliminating salmonella species in the last day of treatment. Similar results were shown by other authors with ciprofloxacin treatment. ${ }^{6,18}$ Before quinolone agents can be used routinely for the treatment of acute diarrhoea the emergence of quinolone resistance should be addressed. Resistance was shown after norfloxacin treatment in six of nine persisting Campylobacter strains that were tested in Wistrom's study. ${ }^{17}$ In The Netherlands $11 \%$ of human Campylobacter isolates were quinolone resistant in $1989 .{ }^{19}$ Plasmidmediated resistance to nalidixic acid in Shigella dysenteriae has recently been reported from an epidemic in Bangladesh. ${ }^{9}$ It was reported that the nalidixic acid resistant strains readily acquired resistance to ciprofloxacin. Clinical resistance to the new quinolones has occurred most often among respiratory pathogens, particularly Pseudomonas aeruginosa from patients with cystic fibrosis and, less frequently, among strains of Serratia marcescens, Pseudomonas aeruginosa and Staphylococcus..$^{20-23}$ So far, overall resistance of bacteria to quinolones has not emerged as a major problem, but like resistance to all other antimicrobial classes, it does occur in certain clinical settings and during indiscriminate use of antibiotics. It seems therefore, that efforts should be invested in defining the patients who definitely require antibiotic treatment. Goodman et al. ${ }^{16}$ showed that the traditional markers of invasive diarrhoea, although predictive of subsequent positive culture, may not be useful when identifying patients who are most likely to benefit from early empiric antimicrobial therapy. Patients without fecal leucocytes, those with negative bacterial cultures, and those with low diarrhoea index scores also appeared to have a shorter clinical illness when treated with ciprofloxacin. These findings are in contrast with those reported by Winstrom who found that the culture positive patients. ${ }^{17}$ Determining whether and which patients should be treated by antibiotic therapy is beyond the scope of this study.

However it seems that effective supportive measures and pharmacological non-antimicrobial therapy ${ }^{24,25}$ should be the mainstay of treatment and antibiotics reserved for severe cases as the benefit of routine empiric antibiotic treatment is low and the danger of emerging bacterial resistance is considerable.

\section{REFERENCES}

1. DuPont H.L. (1987) Diarrhoeal diseases: an overview. American Journal of Medicine 82 (suppl 4A), 329-332.

2. Rogerie F., Ott D., Vandepitte I., Verbist L., Lemmens P. \& Habiyaremye I. (1986) Comparison of norfloxacin and nalidixic acid for treatment of dysentery caused by Shigella dysenteria type I in adults. Antimicrobial Agents and Chemotherapy 29, 883-886.

3. Lolekha S., Patanachareon S., Thanangkul B. \& Vibulbandhitkit S. (1988) Norfloxacin versus cotrimoxazole in the treatment of acute bacterial diarrhea: a placebo controlled study. Scandinavian Journal of Infectious Diseases (Suppl) 56, 35-45.

4. Gotuzzo E., Oberhelman R.A., Maguina C. et al. (1989) Comparison of single dose treatment with norfloxacin and standard 5 day treatment with trimetoprimsulfamethoxazole for acute shigellosis in adults. Antimicrobial Agents and Chemotherapy 33, 1101-1104.

5. DuPont H.L., Corrado M.L. \& Sabbaj J. (1987) Use of norfloxacin in the treatment of acute diarrheal diseases. American Journal of Medicine 82 (suppl 6B), 79-83.

6. Ericcson C.D., Johnson P.C., DuPont H.L. et al. (1987) Ciprofloxacin or trimethoprim-sulfamethoxazole as initial therapy for traveler's diarrhoea. Annals of Internal Medicine 106, 216-220.

7. Pal S.C. (1984) Epidemic bacillary dysentery in West Bengal, India, (letter). Lancet i, 1462.

8. Bennish M., Eusof A., Kay B. \& Wierzba T. (1985) Multiresistant Shigella infections in Bangladesh (letter). Lancet ii, 441.

9. Frost J.A., Willshaw G.A., Barclay E.A. \& Rowe B. (1985) Plasmid characterization of drug-resistant Shigella dysenteriae 1 from an epidemic in Central Africa. Journal of Hygiene (Cambridge) 94, 163-172.

10. Centers for Disease Control. (1986) Multiply resistant Shigell in a day care center-Texas. MMWR 35, 753-755.

11. Centers for Disease Control. (1987) Nationwide dissemination of multiply resistant Shigella sonnei following a common-source outbreak. MMWR 36 , 633-634.

12. Kelly M.T., Brenner D.J. \& Farmer III J.J. (1985) 
Acute bacterial diarrhoea in the emergency room
Enterobacteriacieae. In: Lennette E.H., Belows A., Hausley W.J. Jr \& Shadomy H.J. (eds.) Manual of Clinical Microbiology, 4th ed., pp. 263-277, 302-308. American Society of Microbiology, Washington DC.

13. Morris G.K. \& Patten C.M. (1985) Campylobacter. In: Lennette E.H., Belows A., Hausley W.J. Jr \& Shadomy H.J. (eds.) Manual of Clinical Microbiology, 4th ed., pp. 302-308. American Society of Microbiology, Washington DC.

14. Halpern Z., Dan M., Giladi M., Schwartz I., Sela O. \& Levo Y. (1989) shigellosis in adults: epidemiologic, clinical, and laboratory features. Medicine 68, 210-217.

15. Hyams K.C., Bourgeois A.L., Merrell B.R. et al. (1991) Diarrheal disease during operation desert shield. New England Journal of Medicine 325, 1423-1428.

16. Goodman L.J., Trenholme G.M., Kaplan R.L. et al. (1990) Empiric antimicrobial therapy of domestically acquired acute diarrhoea in urban adults. Archives of Internal Medicine 150, 541-546.

17. Wistrom J., Jertborn M., Ekwall E. et al. (1992) Empiric treatment of acute bacterial disease with norfloxacin. A randomized, placebo-controlled study. Annals of Internal Medicine 117, 202-208.

18. Pichler H.E.T. Diridl G. Stickler K. \& Dietmar W. (1987) Clinical efficiency of ciprofloxacin compared with placebo in bacterial diarrhoea. American Journal of Medicine 82 (Suppl 4A), 329-332.

19. Endtz H.P., Ruijs G.J., van Klingeren B., Jansen
W.H., van der Reyden T. \& Mouton R.P. (1991) Quinoline resistance in campylobacter isolated from man and poultry following the introduction of fluoroquinolnes in veterinary medicine. Journal Antimicrobial Chemotherapy 27, 199-208.

20. LeBel M. (1991) Fluoroquinolones in the treatment of cystic fibrosis: A critical reappraisal. European Journal of Clinical Microbiological Infectious Diseases 10, 316-324.

21. Dalhoff A. (1991) Clinical perspectives of quinolone resistance in Pseudomonas aeruginosa. Antibiotics and Chemotherapy 44, 221-239.

22. Masecar B.J. \& Robillard N.J. (1991) Spontanenous quinolone resistance in Serratia marcescens due to a mutation in gyrA. Antimicrobial Agents and Chemotherapy 35, 898-902.

23. Trucksis M., Hooper D.C. \& Wolfson J.S. (1991) Emerging resistance to fluoroquinolones in staphilococci: An alert. Annals of Internal Medicine 114, 424-426.

24. DuPont H.L., Ericson C.D. \& Mathewson J.J. (1993) Zaldaride Maleate, an intestinal Calmodulin inhibitor, in the treatment of traveler's diarrhea. Gastroenterology 104, 709-715.

25. Figueroa-Quintanilla D., Salazar-Lindo E. \& Sack R.B. (1993) Acontrolled trial of bismuth subsalicylate in infants with acute wattery diarrhoeal disease. New England Journal of Medicine 328, 1653-1658. 